\title{
Changes in turbidity and human activities along Haihe River Basin during lockdown of COVID-19 using satellite data
}

\author{
Xu Chen ${ }^{1} \cdot$ Wei Chen ${ }^{2}$ [D $\cdot$ Yanbing Bai ${ }^{3} \cdot$ Xiaole Wen $^{1}$ \\ Received: 24 May 2021 / Accepted: 7 August 2021 / Published online: 14 August 2021 \\ (C) The Author(s), under exclusive licence to Springer-Verlag GmbH Germany, part of Springer Nature 2021
}

\begin{abstract}
During the outbreak of the COVID-19, China implemented an urban lockdown in the first period. These measures not only effectively curbed the spread of the virus but also brought a positive impact on the ecological environment. The water quality of urban inland river has a significant impact on urban ecology and public health. This study uses Sentinel-2 visible and nearinfrared band reflectance and the Normalized Difference Turbidity Index (NDTI) to analyze the water quality of the Haihe River Basin during the control period of COVID-19. It is found that during the lockdown period, the river water quality was significantly improved compared to the same period in 2019. The average NDTI of the Haihe River Basin in March decreased by 0.27, a decrease of $219.06 \%$; in April, it increased by 0.07 , that is $38.38 \%$. Further exploration using VIIRS lights found that the brightness of the lights in the main urban area was significantly lower in February, the beginning of the lockdown. However, as the city was unblocked, the lights rose sharply in March and then recovered to normal. There is obvious asynchrony in changes between river turbidity and light. The results can help understand the impact of human activities on the natural environment.
\end{abstract}

Keywords Water quality $\cdot$ NDTI $\cdot$ COVID-19 lockdown $\cdot$ VIIRS $\cdot$ Sentinel-2

\section{Introduction}

Water is the source of life. Facing the increasingly serious shortage of fresh water and pollution of the water, remote sensing-based monitoring of water has received widespread attention. Urban rivers are closely related to the lives of urban residents, and remote sensing data has also been widely used to monitor changes in water quality of urban river (Kritikos et al. 1974; Ritchie et al. 1976; Moore 1980). However, in actual situations, many factors affect the spectral characteristics of water, such as atmospheric conditions, satellite observation angles, water depth, suspended solids, and colored

Responsible Editor: Philippe Garrigues

Wei Chen

chenwei19@tju.edu.cn

1 College of Environment and Resources, Fuzhou University, Fuzhou 350108, China

2 Institute of Surface-Earth System Science, School of Earth System Science, Tianjin University, Tianjin 300072, China

3 Center for Applied Statistics, School of Statistics, Renmin University of China, Beijing 100872, China dissolved organic matter (Anji Reddy 1993; Doxaran et al. 2002; Lim and Choi 2015). Due to the complexity of water quality remote sensing, the current water quality remote sensing is mainly limited to colored organic matter, chlorophyll, and turbidity (Gholizadeh et al. 2016; Trinh et al. 2017; Chander et al. 2019; Luis et al. 2019). Among the water quality parameters of river water, suspended solids are the easiest to observe intuitively and have quite common problems. Suspended matter causes the attenuation of light in the river, resulting in decreased aquatic organisms (Garg et al. 2017). The increase of suspended solids is often artificially regarded as one of the indicators of river water eutrophication (Güttler et al. 2013; Sebastia-Frasquet et al. 2019). Previous studies have found that turbidity is closely related to suspended solids particles and water depth (Sebastia-Frasquet et al. 2019). Therefore, the monitoring of water turbidity is of great significance to the management of the rivers and lakes.

Turbidity is an important optical characterization parameter of water body. The change of the concentration of suspended matter will change the light propagation direction in the water and cause the attenuation of light energy (Sebastia-Frasquet et al. 2019). Turbidity will increase with the increase of suspended solids and sediment concentration in water (Garg et al. 2017). Both climate change and human activities can 
cause changes in turbidity (Luis et al. 2019). In recent years, remote sensing technology has been widely used to observe this characteristic of the river by analyzing how the concentration of suspended sediment affects the optical characteristics of water. In the visible range, especially the red band, the reflectance increases with the increase of water turbidity, and previous studies have found that the near-infrared band is also sensitive to turbidity (Toming et al. 2016).

During the 2 years, COVID-19 has become the most serious epidemic in the world, affecting more than 210 countries, which is still spreading (Chauhan and Singh 2020; Paital et al. 2020; Saadat et al. 2020). In response to this situation, different countries and regions have announced a lockdown period. Related studies have found the improvements of the environmental conditions of major cities around the world during urban lockdown, such as the water and air pollution improvements (Braga et al. 2020; Collivignarelli et al. 2020; Dantas et al. 2020; Lal et al. 2020; Li et al. 2020; Muhammad et al. 2020; Otmani et al. 2020; Zheng et al. 2021). China's air quality has improved significantly during the lockdown, while there are few studies on the changes in the water quality during the lockdown (He et al. 2020).

As one of the widely used products for earth observation, night light data can well show the brightness of artificial lighting (Falchi et al. 2016). The Visible Infrared Imaging Radiometer Suite (VIIRS) Day/Night Band (DNB) jointly released by National Aeronautics and Space Administration (NASA)/National Oceanic Administration and Atmospheric Administration (NOAA) is further improved on the basis of DMSP and is currently the most widely used night global optical imaging products. Night light data can represent the status of regional economic and social development. Additionally, light data is very sensitive to disasters, wars, and economic recession (Elvidge et al. 1999; Kohiyama et al. 2004; Román et al. 2019; Li and Li 2014; Coscieme et al. 2017; Elvidge et al. 2017). The lockdown of COVID19 has caused drastic changes in the intensity of regional residents' activities, which can be well characterized on the light map. To analyze the intensity changes of residents' activity during the epidemic, we used the low-light imaging satellite data collected by the NASA/NOAA. Considering the large influence of the cloud, the use of cloudless monthly composite data can eliminate the influence of the cloud and obtain continuous data. Through the analysis of light intensity changes, the impact of the lockdown on residents' activities can be studied.

In this study, to explore the impact of lockdown on water environment, the visible band reflectance and the normalized difference turbidity index (NDTI) of Sentinel-2 data were used to analyze the changes in river quality before and after the lockdown. Through the monitoring of the water turbidity of the river, it is found that the water quality has changed significantly during the lockdown of COVID-19. The VIIRS night data was also utilized to analyze the changes in human activities as well as its relationship with water quality changes.

\section{Materials and methods}

\section{Study area}

The Haihe River is one of the seven major rivers in China and acts as the largest watershed in North China. There are many tributaries for the Haihe River. The three main tributaries of Xinkai River, Beiyun River, and Ziya River converge into the main stream of the Haihe River in the center of Tianjin and flow into the Bohai Sea. The water quality of the Haihe River mainly affects the production and lives of Tianjin residents. The study area is the three tributaries (Xinkai River, Beiyun River, and Ziya River) that enter Tianjin and the main stream of the Haihe River (Fig. 1). Tianjin is the most important industrial city in northern China and also one of the most densely populated cities. The Haihe River is affected by both industrial pollution and urban sewage and the water pollution is quite serious (Jiang et al. 2007).

\section{Data and preprocessing}

Sentinel-2A and Sentinel-2B were launched on June 23, 2015, and March 7, 2017, and their multi-spectrum scanners carry 13 channels. The range covers the visible to near-infrared wavelengths. The details of each band are shown in Table 1 (Garg et al. 2020). The data used is shown in Table 2. All cloud-free data are downloaded from the Sentinel Data Center (https://scihub.copernicus.eu/dhus/\#/home). All data in this study have been geometrically corrected and radiometrically calibrated.

The cloudless monthly synthetic VIIRS DNB products of the study area was downloaded from the Colorado School of Mines Data Center (https://eogdata.mines.edu/products/vnl/) and shown in Fig. 2.

Precipitation has a great influence on water turbidity, so it is necessary to collect and analyze precipitation data during the study period. The precipitation data is collected from the National Meteorological Science Data Center (http://data. cma.cn/) and shown in Fig. 3.

\section{Water extraction and NDTI}

In order to monitor the changes in river water quality, the extraction of the river must first be performed. According to the characteristics of water in Sentinel-2 data (Table 2), the normalized difference water index (NDWI) was selected to extract the water: 


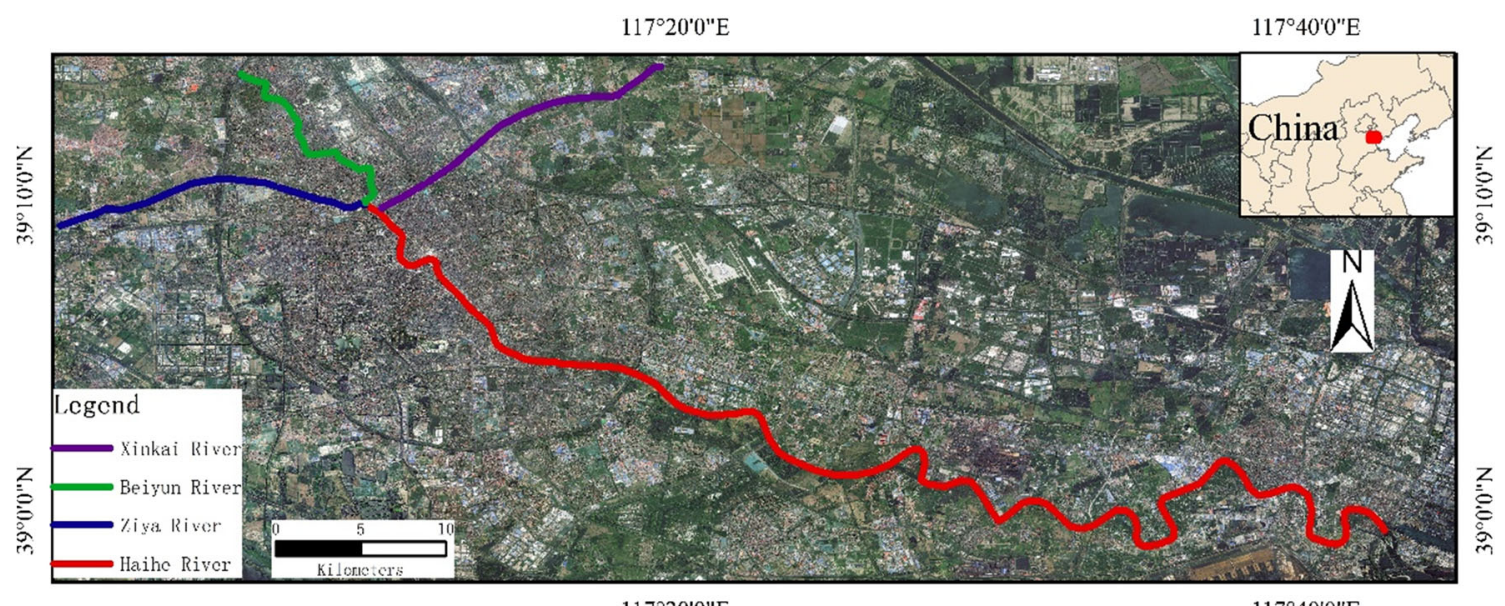

$117^{\circ} 20^{\prime} 0^{\prime \prime E}$

$117^{\circ} 40^{\prime} 0^{\prime \prime} \mathrm{E}$

Fig. 1 Location of the study areas

$N D W I=\frac{R_{G}-R_{N I R}}{R_{G}+R_{N I R}}$

where $R_{G}$ and $R_{N I R}$ are the reflectance of the green band and the near-infrared band. Since water has a high reflectance in the green band, and electromagnetic radiation in the nearinfrared band is almost completely absorbed, the theoretical value of NDWI ranges from -1 to +1 and values greater than 0 are regarded as water.

Previous studies have found that the change of water turbidity makes the water reflectance change significantly (Liedeke et al. 1995; Brezonik et al. 2005). In the field of remote sensing, due to the similarity of suspended solids concentration and turbidity, turbidity is used uniformly in this study. Researchers have also found that when the water turbidity changes significantly, even a single band data can be used to effectively estimate the turbidity (Nechad et al. 2010). Some scholars used a single near-infrared band data to estimate the water turbidity, while some used a single red band reflectance. More studies found that band combinations can be used to estimate turbidity better than single band (SebastiaFrasquet et al. 2019). Here, we analyzed the spectral changes in the blue to near-infrared bands due to turbidity changes and then applied the density division method to divide the water reflectance into three categories. As the sediment concentration increases, the visible band reflectance increases, and vice versa. Therefore, areas with higher reflectance are regarded as with higher turbidity.

However, because relying on a single band may cause large errors, considering the previous findings, here we selected the Normalized Difference Turbidity Index (NDTI) to estimate the turbidity of water (Kuhn et al. 2019; Lacaux et al. 2007; Pahlevan et al. 2019):

$N D T I=\frac{R_{R}-R_{G}}{R_{R}+R_{G}}$
Table 1 Sentinel-2 Multispectral Imager bands and their details

\begin{tabular}{lll}
\hline Band(wavelength) & Central wavelength (nm) & Resolution (m) \\
\hline Band 1 (coastal aerosol) & 443 & 60 \\
Band 2 (blue) & 490 & 10 \\
Band 3 (Green) & 560 & 10 \\
Band 4 (Red) & 665 & 10 \\
Band 5 (vegetation red edge) & 705 & 20 \\
Band 6 (vegetation red edge) & 740 & 20 \\
Band 7 (vegetation red edge) & 783 & 20 \\
Band 8 (NIR) & 842 & 10 \\
Band 8A (vegetation red edge) & 865 & 20 \\
Band 9 (water vapor) & 945 & 60 \\
Band 10 (SWIR-Cirrus) & 1375 & 60 \\
Band 11 (SWIR) & 1610 & 20 \\
Band 12 (SWIR) & 2190 & 20 \\
\hline
\end{tabular}


Table 2 Sentinel-2 acquisition data used in this study and the sensor types

\begin{tabular}{ll}
\hline Data acquisition date & Sensor type \\
\hline January 25, 2019 & Sentinel-2A \\
February 4, 2019 & Sentinel-2A \\
March 16, 2019 & Sentinel-2A \\
April 15, 2019 & Sentinel-2A \\
May 20, 2019 & Sentinel-2B \\
January 20, 2020 & Sentinel-2A \\
February 4, 2020 & Sentinel-2B \\
March 15, 2020 & Sentinel-2A \\
April 14, 2020 & Sentinel-2B \\
May 19, 2020 & Sentinel-2A \\
\hline
\end{tabular}

where $R_{R}$ is the reflectance in the red band and $R_{G}$ is the reflectance in the green band. The reflectance in the red band increases with the increase of turbidity, so the application of these two bands can well identify the turbidity change. The larger the NDTI, the higher the turbidity.

\section{Statistics of lighting data}

Although the light used is the monthly composite data, there are still many interference factors, including clouds and moonlight. To eliminate these errors, the "darkest pixel" method is selected for data correction. The water area is regarded as a completely dull area, and the stray light is eliminated by

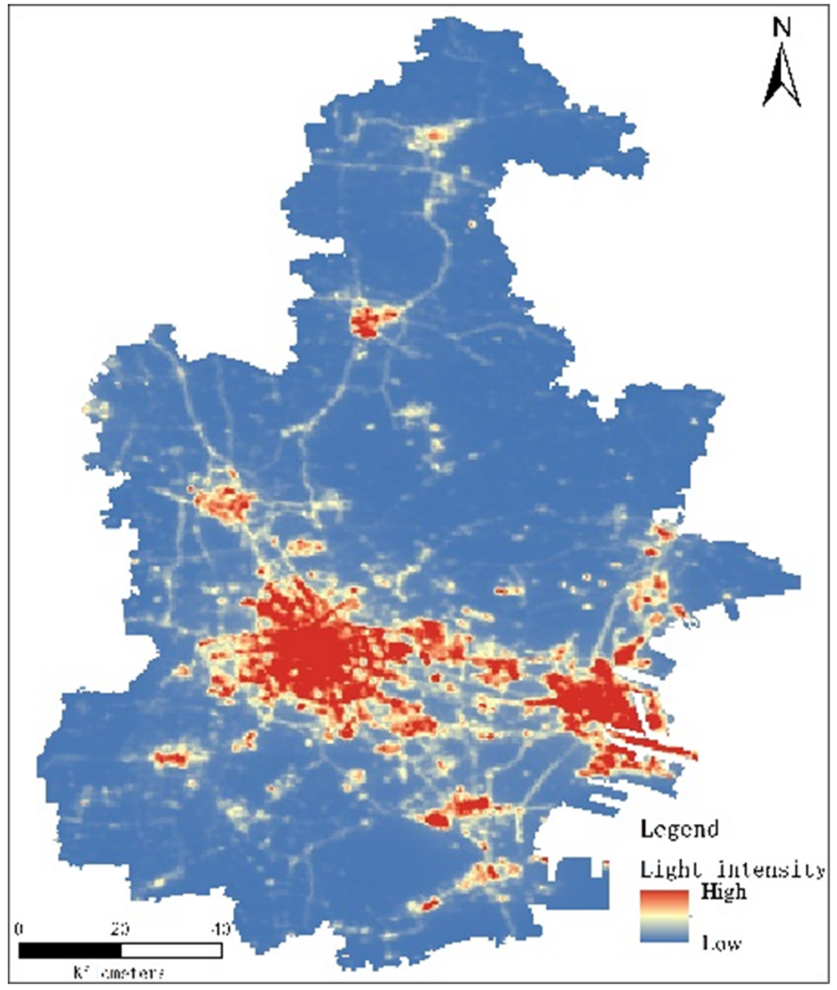

Fig. 2 Monthly synthetic cloud-free DNB of Tianjin

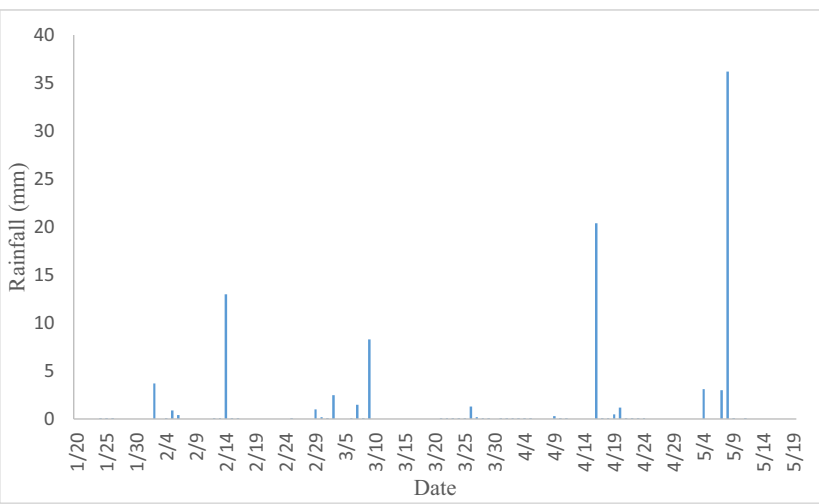

Fig. 3 Rainfall at each location during January 20-May 19, 2020

subtracting the brightness of the light in the water. In order to objectively reflect the light intensity changes, the water area is buffered; the light changes during the lockdown period were analyzed, and then the changes of the residents' production and life intensity can be correlated.

\section{Significant analysis of NDTI and light intensity changes}

To study the significant relationship between changes in NDTI and light intensity, a significant analysis of NDTI and light intensity was performed. Considering the small number of samples, a $t$-test was used (Yang et al. 2019).

\section{Results}

Due to the lockdown caused by COVID-19, the residents' activities have undergone drastic changes, which have led to major changes in the water quality of the study area. In order to be able to clearly discover these changes, we visualized the Sentinel-2 multispectral data from January to May 2020. In addition, the normalized turbidity index was used to quantitatively analyze the changes in water turbidity and was compared with that of the same period in 2019. Simultaneously, the night light data is used to assist the analysis of the water quality change process.

\section{Change in reflectance in single band of Sentinel-2}

In view of the fact that the Haihe River is composed of three tributaries converging in the center of Tianjin, the three tributaries and the Haihe River were studied separately. The reflectance of river water in different periods is greatly affected by rainfall.

The Xinkai River flows from the northeast into the city center and joins the Haihe River. From Fig. 4, we can clearly observe the monthly change of the Sentinel-2 reflectance of Xinkai River during January-May. Overall, the red, green, 


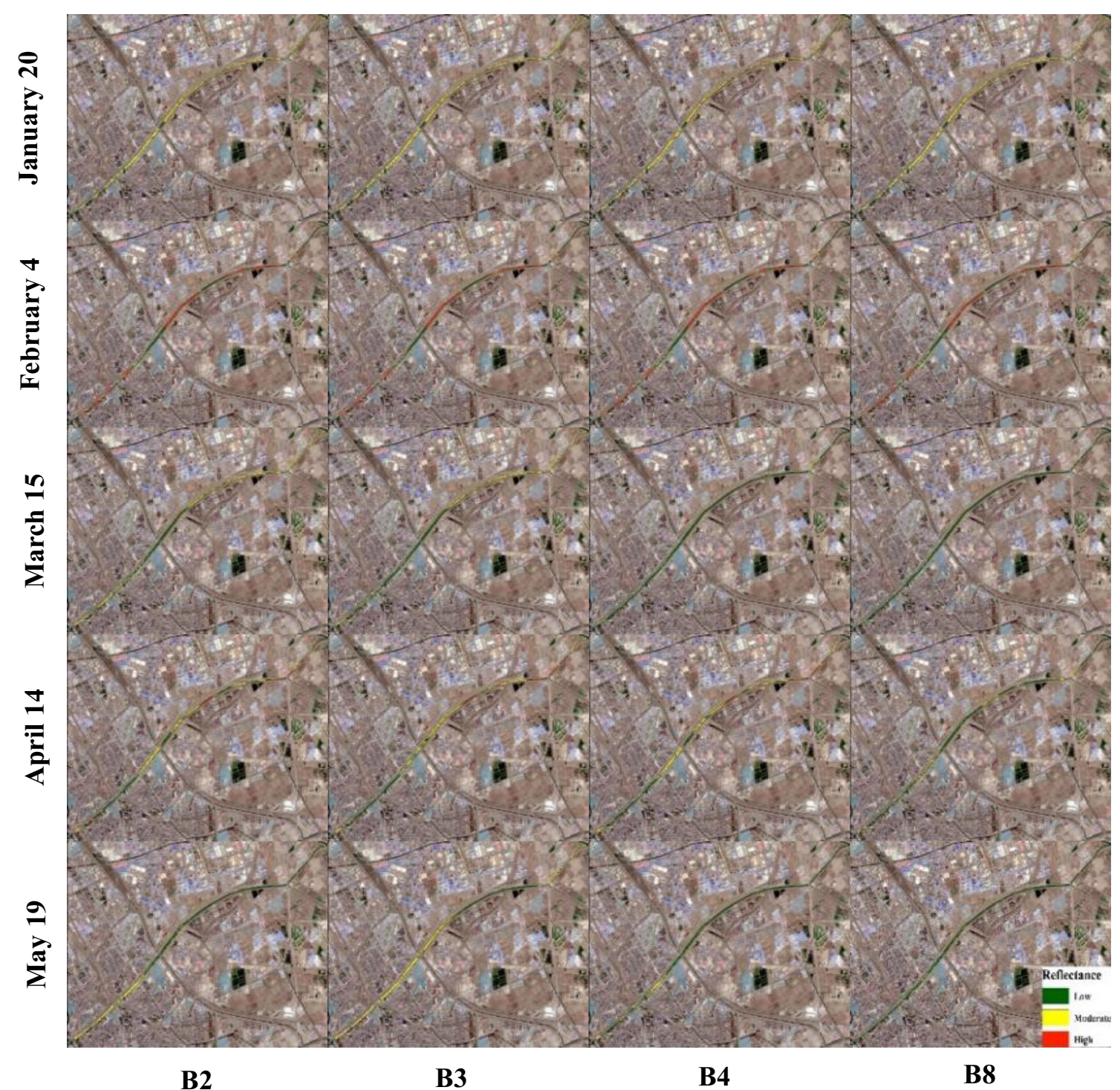

Fig. 4 The Xinkai River change its reflectance in visible to NIR bands of Sentinel-2 on respective dates

and blue bands are consistent with the near-infrared bands, that is, when the turbidity is high, the reflectance of the four bands is higher and vice versa. Compared with January 20 and February 4, the reflectance of the blue, green, red, and nearinfrared bands in the middle and lower reaches of the river increased significantly, and the turbidity of the river increased. It should be noted that there was rain on February 1 and February 4, which caused a significant increase in the turbidity of the river on February 4. The most obvious was the blue, green, red, and nearinfrared all over the area on March 15. The overall reflectance of all bands has decreased, and the water quality was significantly improved, reaching the best level during this period. There was a slight increase in the reflectance of the visible light band on April 14 . The reflectance of blue, green, red, and near-infrared bands did not change significantly on May 19.
The Beiyun River flows from the northwest to the city center and merges into the Haihe River. The reflectance changes of the Beiyun River in the single bands of Sentinel2 are shown in Fig. 5. Compared with January 20, the reflectance in the blue, green, red, and near-infrared bands in the upper and middle part of the river decreased on February 4 and so did the turbidity. It should be noted that there was rainfall on February 1 and February 4, which caused an increase in turbidity and reflectance in the downstream. The most obvious was the overall decrease in the reflectance in the blue, green, red, and near-infrared bands on March 15, when the water quality was significantly improved. After that, the single band reflectance and the turbidity increased on April 14. On May 19, the reflectance and the turbidity decreased again.

The Ziya River flows from west to east into the city center and merges into the Haihe River. The reflectance changes of 
Fig. 5 The Beiyun River change its reflectance in visible to NIR bands of Sentinel-2 on respective dates

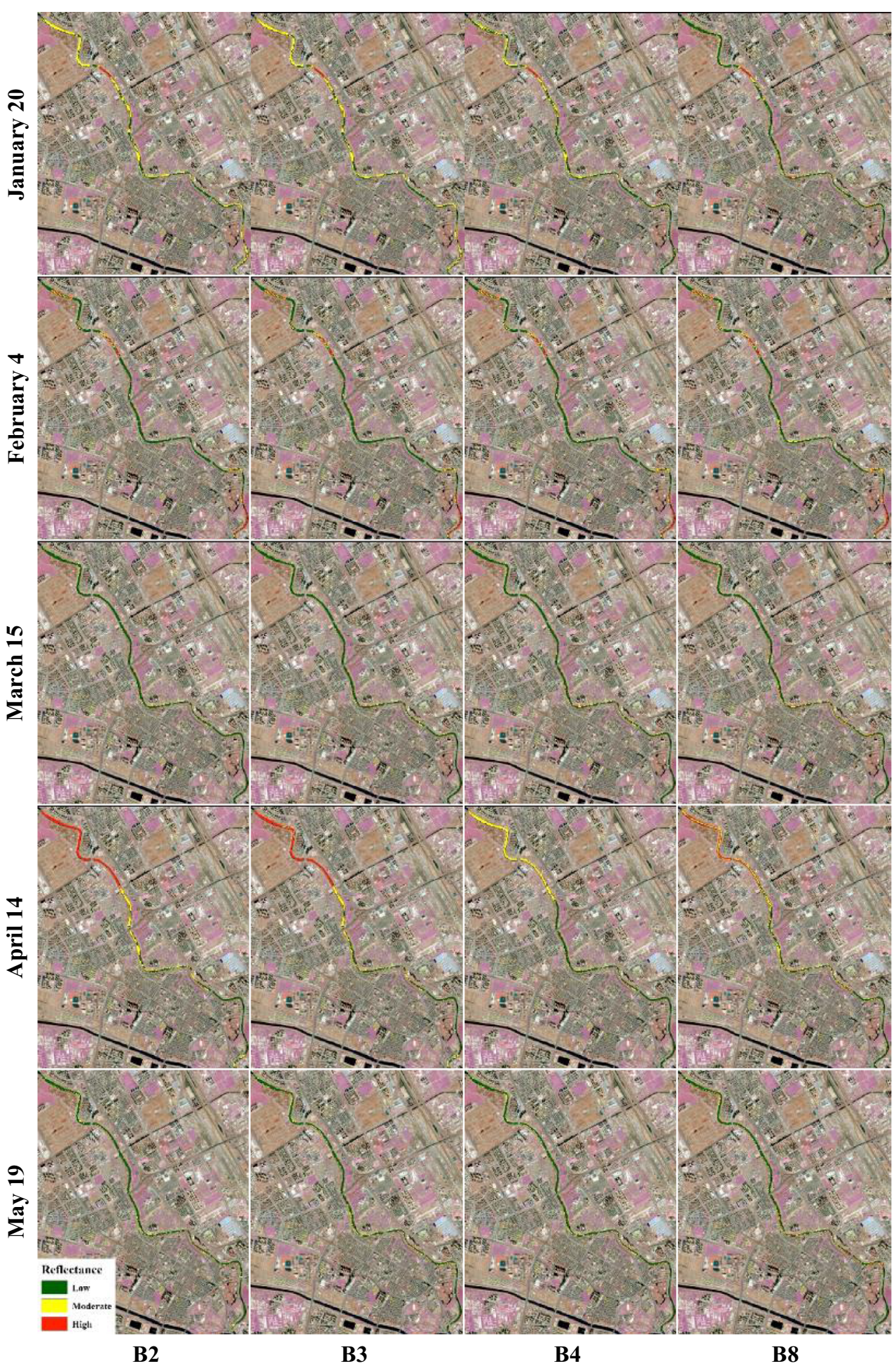

Ziya River in Sentinel-2 single bands are shown in Fig. 6. Compared with January 20, the blue, green, red and nearinfrared reflectance as well as turbidity increased on February 4. Compared with the Xinkai River and the Beiyun River, the reflectance in all bands has increased more drastically. This is due to a large amount of bare land along the Ziya
River. The rainfall event in early February brought a large amount of coastal soil into the river, and thus the concentration of suspended solids in the river increased significantly. The reflectance of all visible and near-infrared bands all decreased on March 15, and the water quality was significantly improved. On April 14, both the reflectance and the turbidity 
Fig. 6 The Ziya River change its reflectance in visible to NIR bands of Sentinel-2 on respective dates

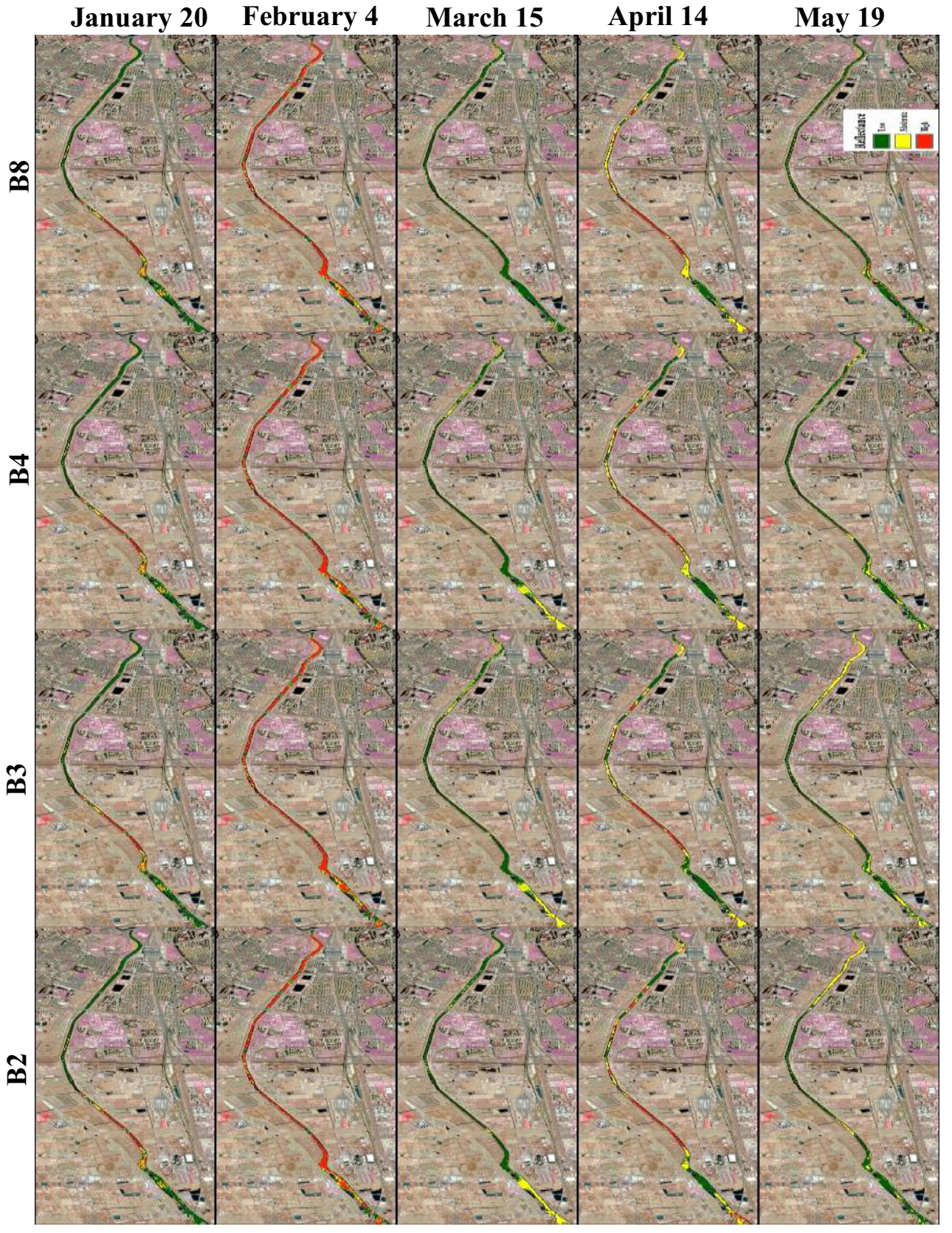

increased. The reflectance did not change significantly on May 19 and so did the turbidity.

The Xinkai River, Beiyun River, and Ziya River converge to the Haihe River in the Tianjin city center. The reflectance changes in red, green, blue, and near-infrared bands of Sentinel-2 in the Haihe River are shown in Fig. 7. Compared with January 20, the reflectance in the four single bands in the upper reaches of the river increased on February 4 and so did the turbidity. The single band reflectance in the whole region decreased on March 15, especially in the near-infrared bands, and the water quality was significantly improved. However, the reflectance in visible bands did not change significantly on April 14, but increased in near-infrared band for the upstream area. On May 19, the reflectance of the upstream in red and near-infrared bands decreased, but did not change significantly in other bands.

\section{Spatio-temporal change in NDTI}

Although the reflectance changes in blue, green, red, and nearinfrared bands can show the changes in river turbidity, however, there are some uncontrollable errors due to changes in observation angles and weather conditions (Tassan 1997; Hu et al. 2012; Pahlevan et al. 2019). In order to quantitatively study the changes in turbidity, the NDTI of river was observed. Through the analysis of the NDTI of the river, a deeper 
Fig. 7 The Haihe River change its reflectance in visible to NIR bands of Sentinel-2 on respective dates

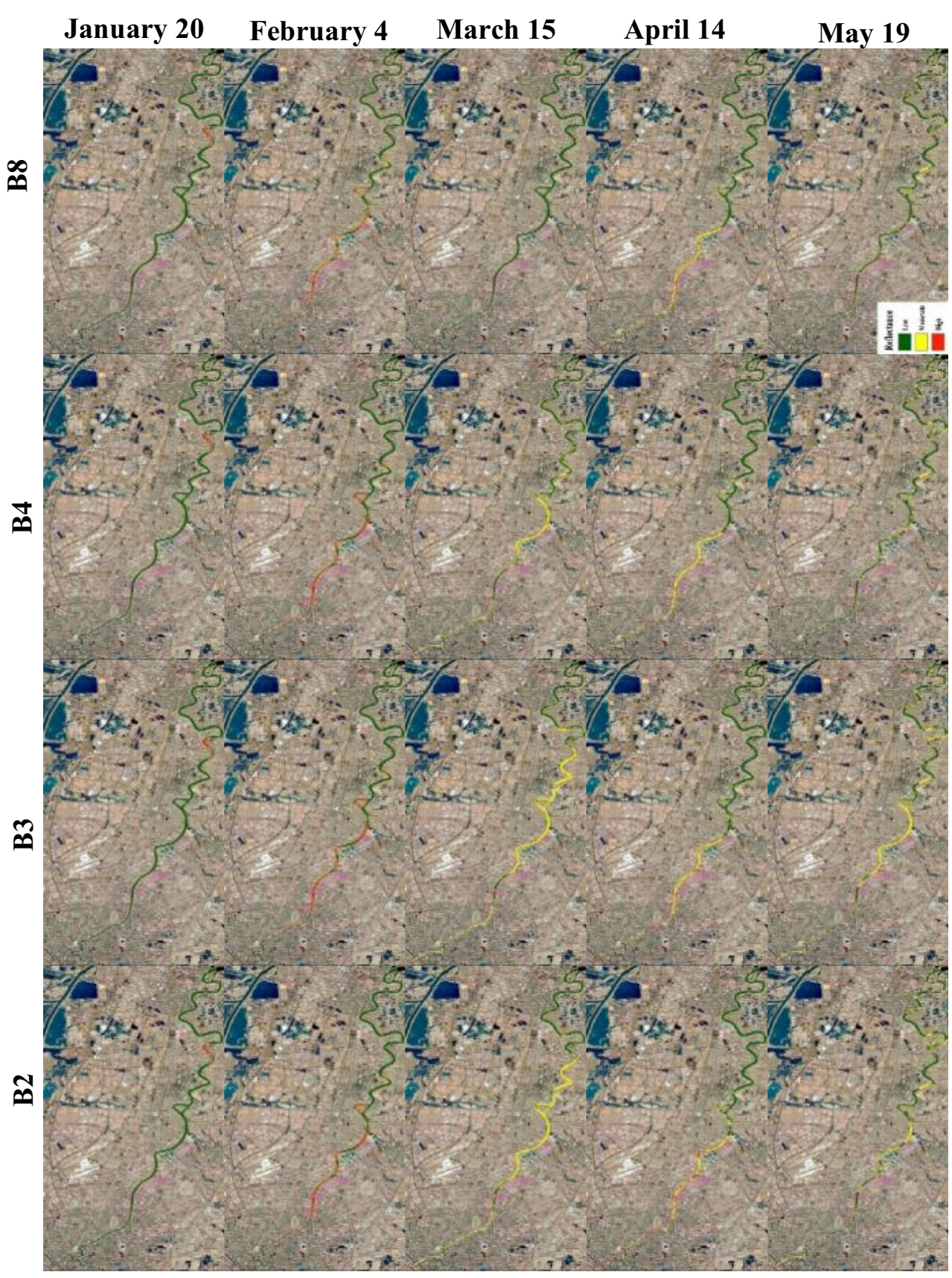

understanding of the changes in river turbidity can be obtained.

We can clearly see the changes in the NDTI of the Xinkai River in Fig. 8 (the point location diagram is in the Supplementary Information). It is significant that the NDTI was the lowest in March. In April and May, when the lockdown was gradually lifted, NDTI increased significantly. Additionally, the changes in NDTI between the same period of 2019 and 2020 were compared (Fig. 9). It can be found that in March 2020, the NDTI was significantly lower than that in 2019. For other periods, there is no significant difference.
The NDTI change trend in the Beiyun River and Xinkai River are similar (Fig. 10). The NDTI in March was much lower than in other months. Although in March 2020, there are small areas with NDTI greater than 2019 (Fig. 11), they are much lower in 2020 than 2019 for most areas.

The NDTI changes in the Ziya River are also similar to those of the Beiyun and Xinkai Rivers (Fig. 12). The NDTI in March was much lower than in other months. The NDTI in most areas is still much lower in 2020 than in 2019, although in some areas of the Ziya River it is the opposite (Fig. 13). 
Fig. 8 The NDTI changes in Xinkai River profile on respective dates
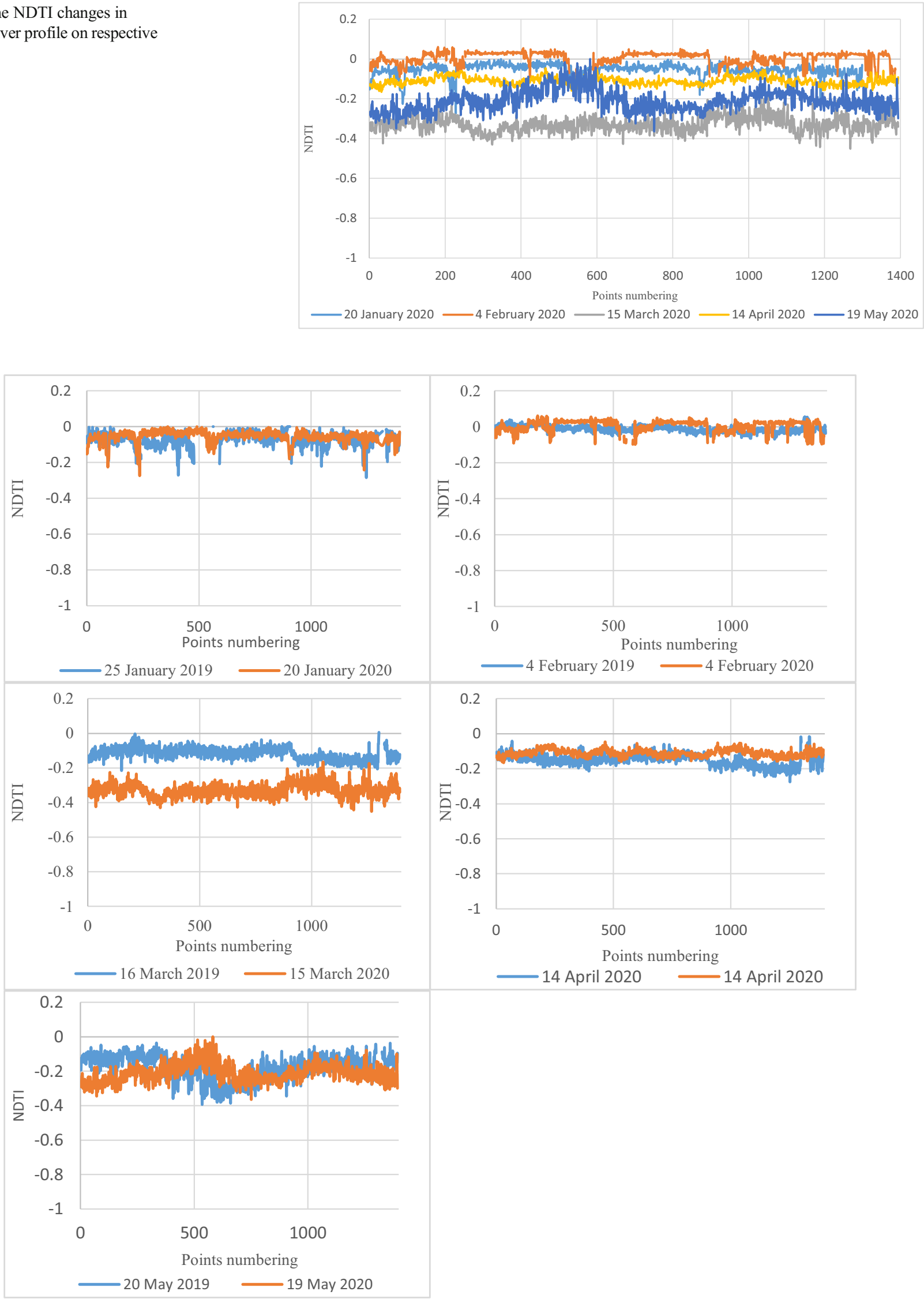

Fig. 9 The NDTI changes in Xinkai River profile between 2019 and 2020 
Fig. 10 The NDTI changes in Beiyun River profile on respective dates

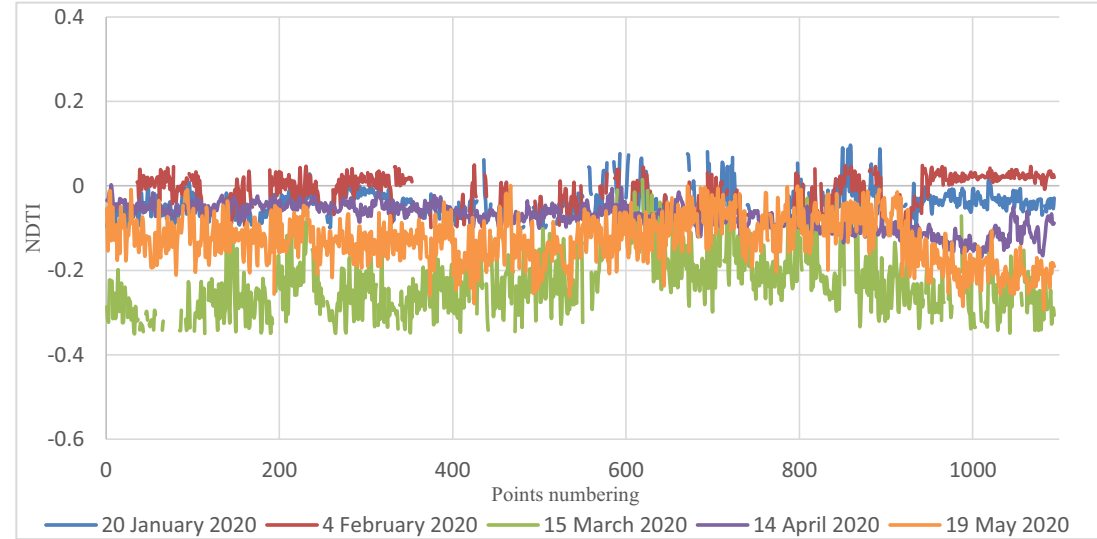

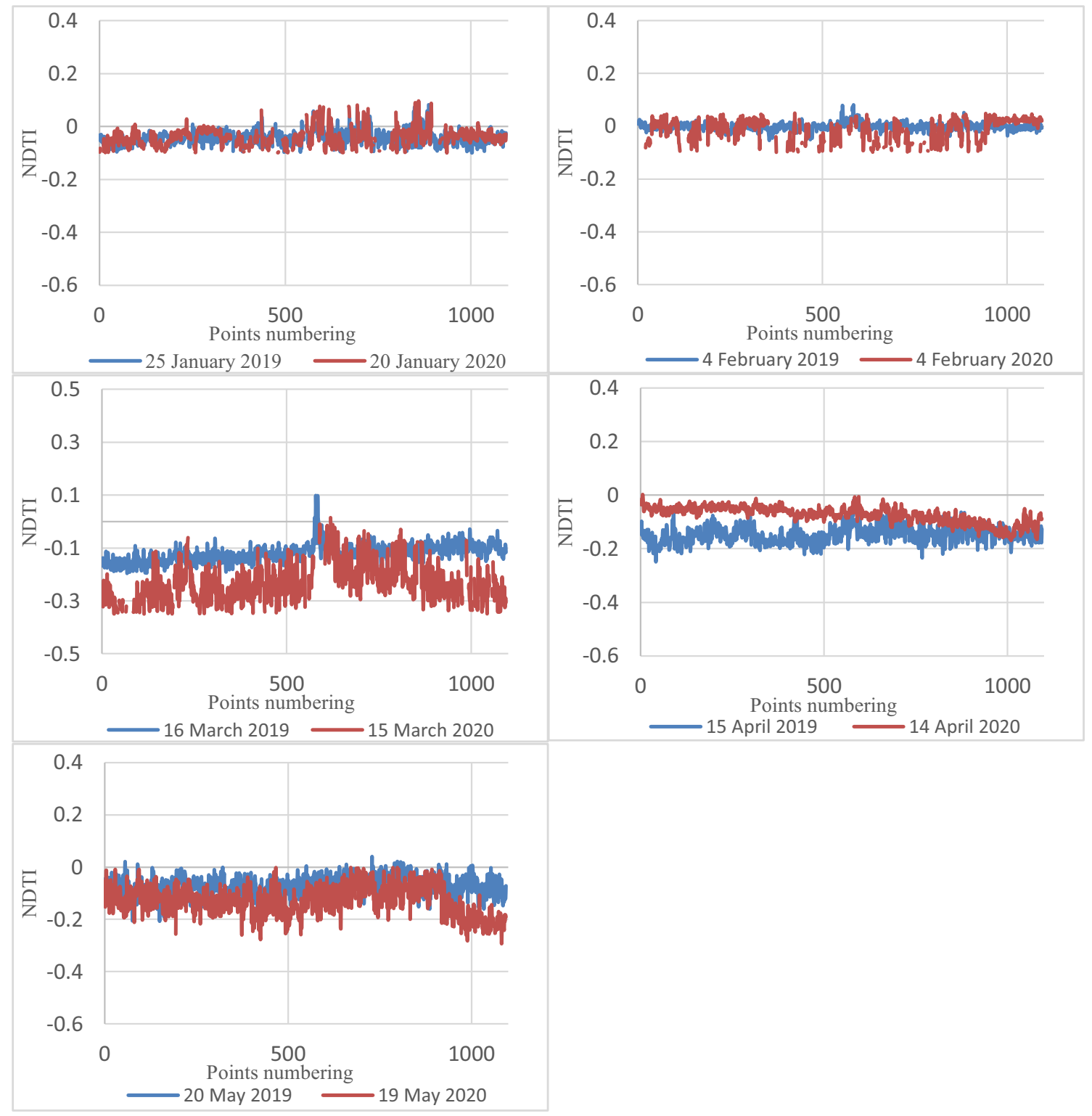

Fig. 11 The NDTI changes in Beiyun River profile between 2019 and 2020 
Fig. 12 The NDTI changes in Ziya River profile on respective dates

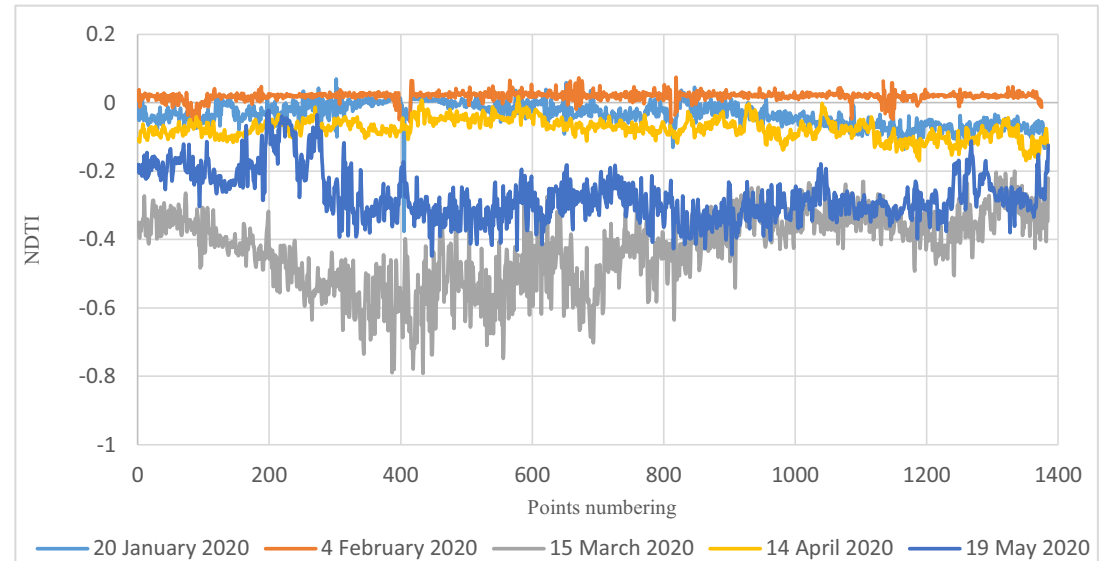

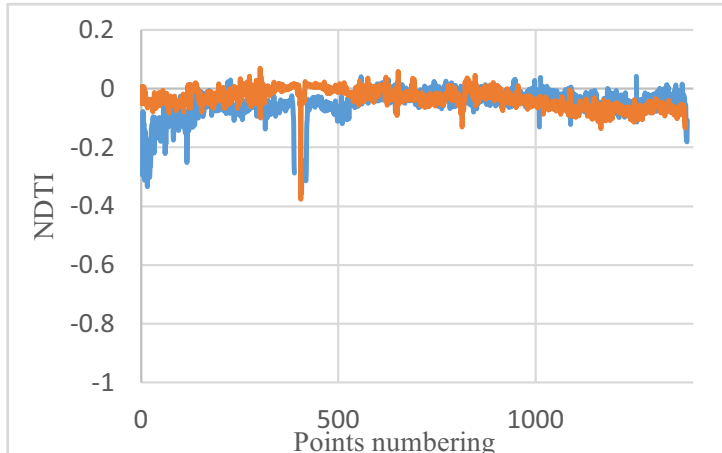
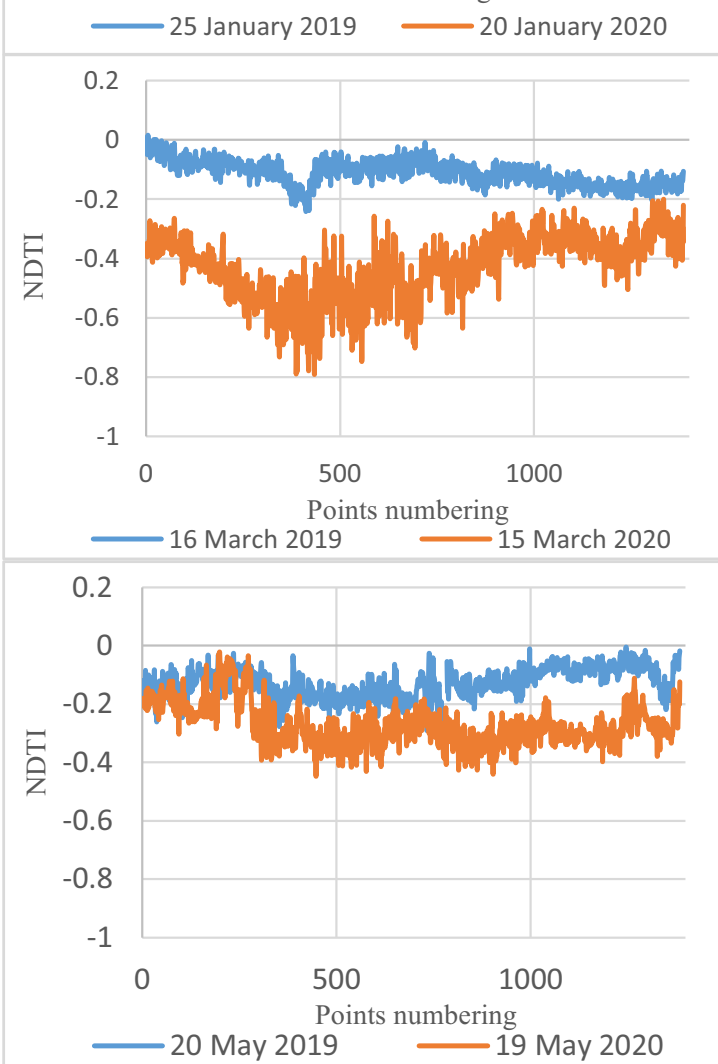

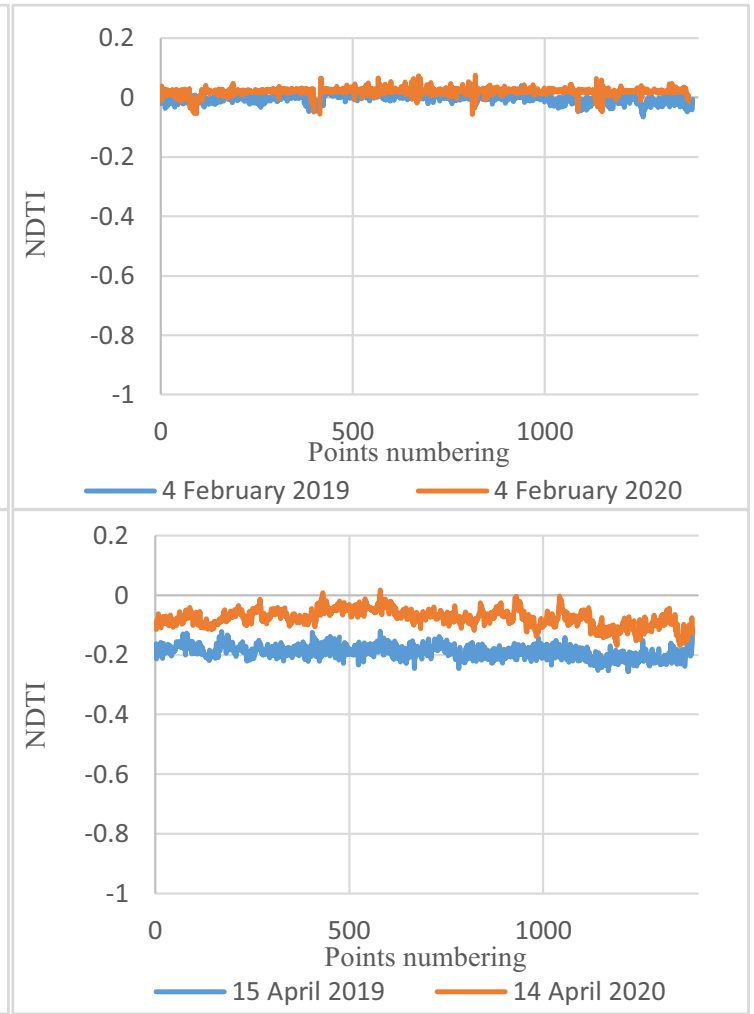

Fig. 13 The NDTI changes in Ziya River profile between 2019 and 2020 
The Haihe River has similar changes in NDTI with the Ziya River, Beiyun River, and Xinkai River (Figs. 14-15). The NDTI in March was much lower than in other months. The NDTI decreased sharply in March 2020 compared with 2019. Due to the influence of precipitation, NDTI increased in April but still low in May.

\section{Changes in night lighting}

The economic development in the region brought great changes in the inter-year lighting data, but the fluctuations between adjacent months are relatively stable. The changes in lighting in the study area between 2019 and 2020 were compared and shown in Fig. 16. It can be found that, the lighting changes in 2020 are more drastic than in 2019. The lighting in February decreased significantly but increased in March. To quantitatively analyze the changes in the lighting, the monthly changes in the lighting were calculated (Table 3 ).

Though $t$-test between NDTI and light intensity under the confidence interval to $95 \%$, the results of $P$ value $<0.01$ indicated that there is significant difference between the two variables.

\section{Discussion}

Through the changes in the water reflectance of the Haihe River basin before and after the lockdown of COVID-19, it was found there are significant changes in water reflectance in the red, green, blue, and near-infrared bands of Sentinel-2 data during 1 month after the lockdown. Reflectance in both visible and near-infrared bands has increased significantly, and the turbidity of the river increased after the reduction of lockdown. The river turbidity after unblocking is similar to that in the same period in previous year. At the same time, the analysis of night lights indicated that the lockdown also caused drastic changes in the lights, which were significantly different from the changes in the turbidity of the water.
According to the $t$-test, there is a significant difference between the two $(P<0.01)$, which can help explain the relationship between human activities and the turbidity of the Haihe River Basin.

Analysis of NDTI in the study area indicated that NDTI first decreased during the lockdown, then increased, and finally returned to the historical normal level. By calculating the changes in NDTI in the study area, it is found that in March, the overall average NDTI decreased by 0.27 , a decrease of $219.06 \%$. Among them, the average value of NDTI in the Xinkai River decreased by 0.19 , a decrease of $170 \%$; that in the Beiyun River decreased by 0.07 , a decrease of $67.29 \%$; that in the Ziya River decreased by 0.28 , a decrease of 299.58\%; and that in the Haihe River decreased by 0.29 , a decrease of $220.75 \%$. In April, the average NDTI increased significantly, and the overall average NDTI increased by 0.07 , an increase of $38.38 \%$. Among them, the average NDTI of Xinkai River increased by 0.04 and $25.25 \%$; that in the Beiyun River decreased by 0.06 , a decrease of $51.43 \%$; that in the Ziya River increased by 0.09 , an increase of $55.91 \%$; and that in the Haihe River increased by 0.08 , an increase of $37.53 \%$. The turbidity in the study area in May did not change significantly compared with 2019.

The light intensity changed significantly in the early stage of the lockdown. Compared with January, the lighting intensity decreased by $20.51 \%$ in February. Through the comparison between changes in light and river turbidity, it is found that there is a similarity, both of which are reduced first, then increased, and finally restored. However, the light intensity changed greatly immediately after the blockade started, but the turbidity of the water did not change significantly until 1 month after the lockdown. This is because the changes in the residents' living intensity caused by the lockdown can be immediately reflected on the light intensity. But the change in river turbidity is closely related to the change of regional pollutant discharge, the inherent environmental state of the river, and the ability of self-purification. Therefore, after a period of lockdown, the reduction of pollutants has decreased
Fig. 14 The NDTI changes in Haihe River profile on respective dates

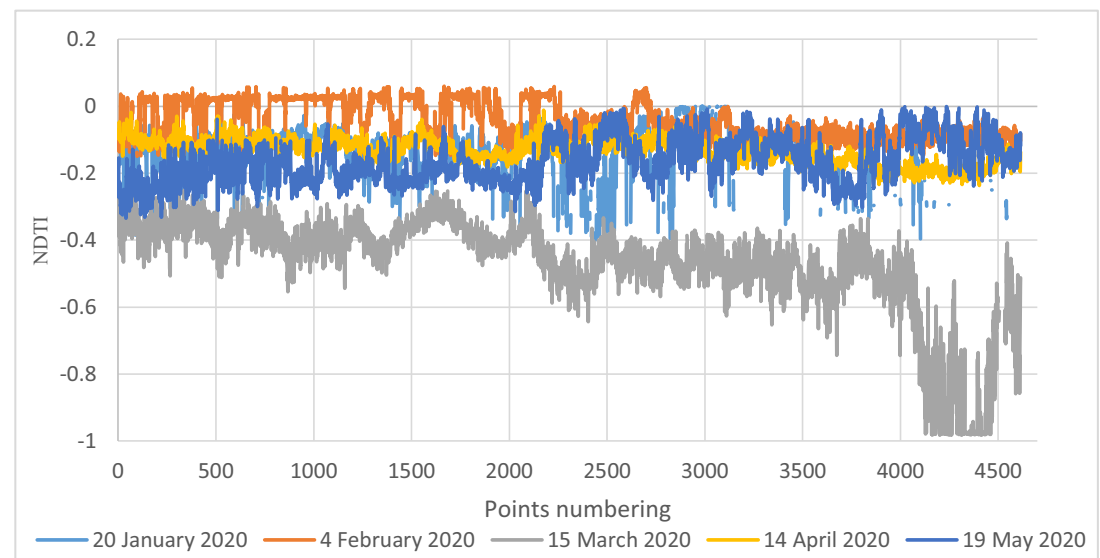




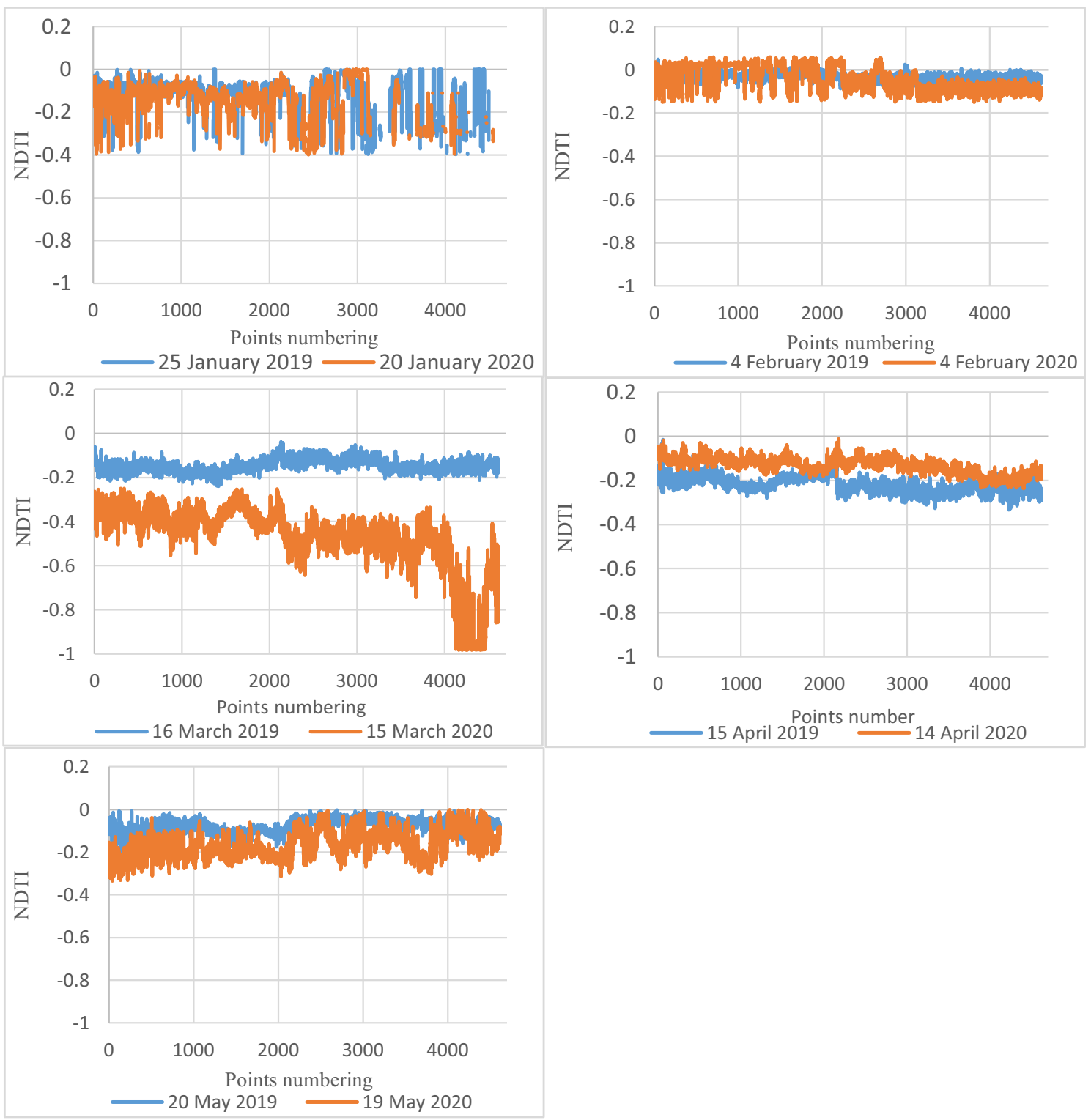

Fig. 15 The NDTI changes in Haihe River profile between 2019 and 2020

Table 3 Monthly change rate of lighting

\begin{tabular}{llllll}
\hline & Year & January to February & February to March & March to April & April to May \\
\hline Xinkai River & 2019 & -12.00 & 17.29 & 3.69 & 3.68 \\
& 2020 & -19.22 & 23.71 & -0.27 & -6.53 \\
Beiyun River & 2019 & -4.12 & 12.44 & 5.49 & 2.52 \\
& 2020 & -16.01 & 15.56 & -1.62 & -5.76 \\
Ziya River & 2019 & -0.66 & 7.03 & 6.47 & 1.52 \\
& 2020 & -18.42 & 27.19 & -4.78 & -11.79 \\
Haihe River & 2019 & -14.65 & 17.71 & 1.66 & 3.80 \\
& 2020 & -21.81 & 23.29 & -0.24 & -4.93 \\
All study area & 2019 & -12.44 & 17.35 & 2.18 & 3.28 \\
& 2020 & -20.51 & 22.95 & -0.83 & -5.33 \\
\hline
\end{tabular}




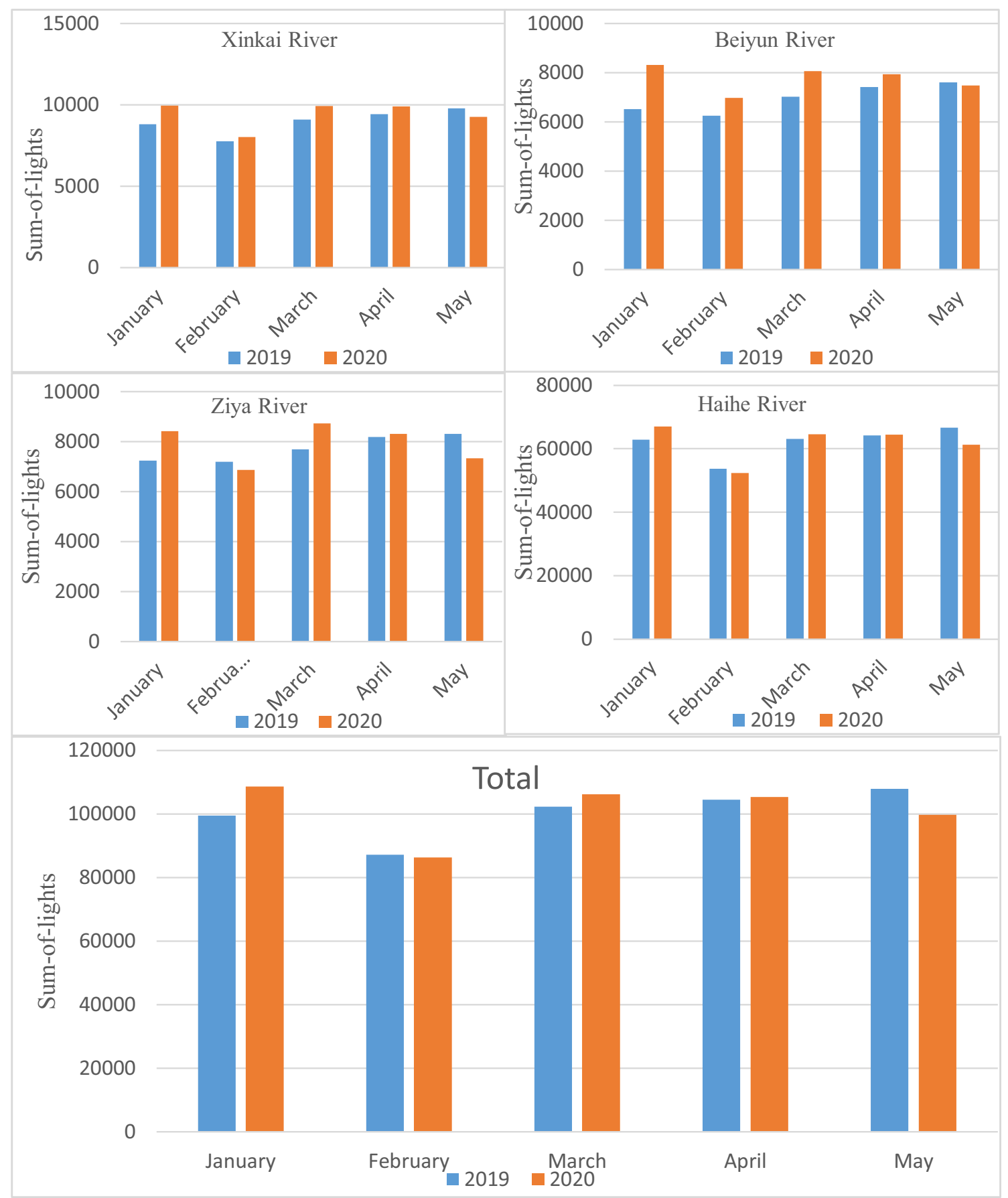

Fig. 16 Lighting changes in the study area in 2019 and 2020

significantly. This finding is consistent with the results of the previous studies (Otmani et al. 2020). The impacts of human activities intervention on the ecological environment may need a certain time to be detected, which cannot appear in a short time. These changes would be detected and monitored in a few days, weeks, or even longer.

In this study, the turbidity changes of the Haihe River Basin in Tianjin before and after the lockdown of COVID19 were characterized. However, since river turbidity is greatly affected by rainfall, human pollution discharge, it is difficult to obtain absolutely accurate river physical and chemical parameters through on-site sampling. The long-term detection and monitoring based on remote sensing data is a potential alternative. This study is a positive attempt.

\section{Conclusions}

Turbidity is an important parameter to characterize the water quality of rivers. It affects the illumination degree 
of the falling water. In this study, the spatio-temporal analysis of water turbidity in the Haihe River Basin during the lockdown of COVID-19 was carried out. It was found that after the lockdown, the reflectance in both the visible and near-infrared bands of Sentinel-2 decreased, due to deceased turbidity. The study of NDTI showed that the turbidity in the study area first decreased, then increased, and finally returned to the historical normal level in the same period. We also analyzed the relationship between river turbidity changes and night light data. The results indicated that from the lockdown of COVID-19, the light intensity decreased significantly at almost the same time, and then the turbidity of the river decreased after 1 month. In the late period of the lockdown, the intensity of the lights increased quickly and then followed by the turbidity of the river. There is a significant difference in changes between NDTI and night light before and after the lockdown. This indicated that changes in the intensity of production and life of residents have a significant impact on the water quality of the river. A major human activity or natural event may cause changes to the surface attributes immediately or after a period of time. A wide variety of satellite data can be used to conduct a comprehensive study on it, especially the night light data which can represent human activities.

Supplementary Information The online version contains supplementary material available at https://doi.org/10.1007/s11356-021-15928-6.

Acknowledgements We thank European Space Agency and Colorado School of Mines for providing free satellite data.

Author contribution Xu Chen and Yanbing Bai developed the concept for the paper, supervised the analysis, and wrote the first draft of the paper; Wei Chen and Xiaole Wen edited the paper and contributed to the conceptualization. Yanbing Bai provided fund.

Funding This research is supported by Public Health \& Disease Control and Prevention, Major Innovation \& Planning Interdisciplinary Platform for the "Double-First Class" Initiative, Renmin University of China, and the fund for building world-class universities (disciplines) of Renmin University of China.

Data availability The datasets used are available from the corresponding author on reasonable request.

\section{Declarations}

Ethics approval and consent to participate Not applicable.

Consent for publication Not applicable.

Conflict of interest The authors declare no competing interests.

\section{References}

Anji Reddy M (1993) Remote sensing for mapping of suspended sediments in Krishna Bay Estuary, Andhra Pradesh. India. Int. J. Remote Sens 14(11):2215-2221

Braga F, Scarpa GM, Brando VE, Manfe G, Zaggia L (2020) COVID-19 lockdown measures reveal human impact on water transparency in the Venice Lagoon. Sci Total Environ 736:139612

Brezonik P, Menken KD, Bauer M (2005) Landsat-based remote sensing of lake water quality characteristics, including chlorophyll and colored dissolved organic matter (CDOM). Lake Reserv. Manag 21(4): 373-382

Chander S, Gujrati A, Hakeem KA, Garg V, Issac AM, Dhote PR, Kumar V, Sahay A (2019) Water quality assessment of River Ganga and Chilika lagoon using AVIRIS-NG hyperspec-tral data. Curr Sci 116(7):1172-1181

Chauhan A, Singh RP (2020) Decline in PM2.5 concentrations over major cities around the world associated with COVID-19. Environ Res 187:109634

Collivignarelli MC, Abba A, Bertanza G, Pedrazzani R, Ricciardi P, Carnevale MM (2020) Lockdown for COVID-2019 in Milan: what are the effects on air quality? Sci Total Environ 732:139280

Coscieme L, Sutton PC, Anderson S, Liu Q, Elvidge CD (2017) Dark times: nighttime satellite imagery as a detector of regional disparity and the geography of conflict. Gisci Remote Sens 54:118-139

Dantas G, Siciliano B, Franca BB, Silva CM, Arbilla G (2020) The impact of COVID-19 partial lockdown on the air quality of the city of Rio de Janeiro, Brazil. Sci Total Environ 729:139085

Doxaran D, Froidefond J-M, Lavender S, Castaing P (2002) Spectral signature of highly turbid waters Application with SPOT data to quantify suspended particulate matter concentrations. Remote Sens Environ. 81(1):149-161

Elvidge CD, Baugh KE, Hobson VR, Kihn EA, Kroehl HW (1999) Detection of fires and power outages using DMSP-OLS data. In: Lunetta RS, Elvidge CD (eds) In Remote Sensing Change Detection: Environmental Monitoring Methods and Applications. Taylor and Francis, London, UK, pp 123-135

Elvidge CD, Hsu FC, Baugh KE, Ghosh T (2017) Lighting tracks transition in Eastern Europe. Springer International Publishing 35-56

Falchi F, Cinzano P, Dan D (2016) The new world atlas of artificial night sky brightness. Science Advances 2(6):e1600377-e1600377

Garg V, Kumar SA, Aggarwal SP, Kumar V, Dhote PR, Thakur PK, Nikam BR, Sambare RS, Siddiqui A, Muduli PR, Rastogi G (2017) Spectral similarity approach for mapping turbidity of an inland waterbody. J Hydrol 550:527-537

Garg V, Aggarwal SP, Chauhan P (2020) Changes in turbidity along Ganga River using Sentinel-2 satellite data during lockdown associated with COVID-19. Geomatics, Natural Hazards and Risk 11(1): 1175-1195

Gholizadeh MH, Melesse AM, Reddi L (2016) A comprehensive review on water quality parameters estimation using remote sensing techniques. Sensors 16(8): 1298

Güttler FN, Niculescu S, Gohin F (2013) Turbidity retrieval and monitoring of Danube Deltawaters using multi-sensor optical remote sensing data: an integrated view from the delta plain lakes to the western-northwestern Black Sea coastal zone. Remote Sens Environ 132:86-101

He GJ, Pan YH, Tanaka T (2020) The short-term impacts of COVID-19 lockdown on urban air pollution in China. Nature Sustainability 3: 1005-1011

Hu C, Lee Z, Franz B (2012) Chlorophyll a algorithms for oligotrophic oceans: a novel approach based on three-band reflectance difference. J Geophys Res 117(C1):C01011

Jiang B, Zheng HL, Huang GQ, Ding H, Li XG, Suo HT, Li R (2007) Characterization and distribution of polycyclic aromatic 
hydrocarbon in sediments of Haihe River, Tianjin, China. Journal of Environmental Sciences 19(3):306-311

Kohiyama M, Hayashi H, Maki N, Higashida KHW, Elvidge CD, Hobson VR (2004) Early damaged area estimation system using DMSP-OLS night-time imagery. Int J Remote Sens 25:2015-2036

Kritikos H, Yorinks L, Smith H (1974) Suspended solids analyses using ERT-A data. Remote Sens Environ 3(1):69-78

Kuhn C, Aline D, Ward N, Loken L, Sawakuchi HO, Kampel M (2019) Performance of Landsat- 8 and Sentinel-2 surface reflectance products for river remote sensing retrievals of chlorophyll-a and turbidity. Remote Sens Environ 224:104-118

Lacaux JP, Tourre YM, Vignolles C, Ndione JA, Lafaye M (2007) Classification of ponds from high-spatial resolution remote sensing: application to Rift Valley Fever epidemics in Senegal. Remote Sens Environ 106(1):66-74

Lal P, Kumar A, Kumar S, Kumari S, Saikia P, Dayanandan A, Adhikari D, Khan ML (2020) The dark cloud with a silver lining: assessing the impact of the SARS COVID-19 pandemic on the global environment. Sci Total Environ 732:13929

Li X, Li DR (2014) Can night-time light images play a role in evaluating the Syrian Crisis? Int J Remote Sens 35:6648-6661

Li L, Li Q, Huang L, Wang Q, Zhu A, Xu J, Liu Z, Li H, Shi L, Li R (2020) Air quality changes during the COVID-19 lockdown over the Yangtze River Delta Region: an insight into the impact of human activity pattern changes on air pollution variation. Sci Total Environ $732: 139282$

Liedeke J, Roberts A, Luternauer J (1995) Practical remote sensing of suspended sediment con-centration. Photogramm Eng Remote Sens 61(2):167-175

Lim J, Choi M (2015) Assessment of water quality based on Landsat 8 operational land imager associated with human activities in Korea. Environ Monit Assess 187(6):384

Luis KMA, Rheuban JE, Kavanaugh MT, Glover DM, Wei J, Lee Z, Doney SC (2019) Capturing coastal water clarity variability with Landsat 8. Mar Pollut Bull 145:96-104

Moore GK (1980) Satellite remote sensing of water turbidity. Hydrol Sci J 25(4):407-421

Muhammad S, Long X, Salman M (2020) COVID-19 pandemic and environmental pollution: a blessing in disguise? Sci Total Environ $728: 138820$

Nechad B, Ruddick K, Park Y (2010) Calibration and validation of a generic multisensor algorithm for mapping of total suspended matter in turbid waters. Remote Sens Environ 114(4):854-866
Otmani A, Benchrif A, Tahri M, Bounakhla M, Chakir EM, Bouch ME, Krombi M (2020) Impact of COVID-19 lockdown on PM10, $\mathrm{SO} 2$ and NO2concentrations in Sale City (Morocco). Sci Total Environ 735:139541

Pahlevan N, Chittimalli SK, Balasubramanian SV, Vellucci V (2019) Sentinel-2/Landsat-8 product consistency and implications for monitoring aquatic systems. Remote Sens Environ 220:19-29

Paital B, Das K, Parida SK (2020) Inter nation social lockdown versus medical care against COVID-19, a mild environmental insight with special reference to India. Sci Total Environ 728:138914

Ritchie J, Schiebe FR, McHenry JR (1976) Remote sensing of suspended sediments in surface waters. Photogramm Eng Remote Sens 42(12): $1539-1545$

Román MO, Stokes EC, Shrestha R, Wang Z, Schultz L, Carlo ES, Sun Q, Bell J, Molthan A, Kalb V (2019) Satellite-based assessment of electricity restoration efforts in Puerto Rico after Hurricane Maria. PLoS ONE 14:e0218883

Saadat S, Rawtani D, Hussain CM (2020) Environmental perspective of COVID-19. Sci Total Environ 728:138870

Sebastia-Frasquet MT, Aguilar-Maldonado JA, Santamarı-Del-Angel E, Estornell J (2019) Sentinel 2 analysis of turbidity patterns in a coastal lagoon. Remote Sens 11(24):2926

Tassan S (1997) A numerical model for the detection of sediment concentration in stratified river plumes using Thematic Mapper data. Int J Remote Sens 18(12):2699-2705

Toming K, Kutser T, Laas A, Sepp M, Paavel B, Noges T (2016) First experiences in mapping lake water quality parameters with Sentinel2 MSI imagery. Remote Sens 8(8):640

Trinh RC, Fichot CG, Gierach MM, Holt B, Malakar NK, Hulley G, Smith J (2017) Application of Landsat 8 for monitoring impacts of wastewater discharge on coastal water quality. Front Mar Sci 4:329

Yang WZ, Zhang T, Wang GP (2019) SPSS statistical analysis and detailed explanation of industry application cases, 4th edn. Tsinghua University Press

Zheng S, Fu Y, Sun Y, Zhang CJ, Wang YS, Lichtfouse E (2021) High resolution mapping of nighttime light and air pollutants during the COVID-19 lockdown in Wuhan. Environ Chem Lett 19:3477-3485

Publisher's note Springer Nature remains neutral with regard to jurisdictional claims in published maps and institutional affiliations. 